\title{
Teaching professionalism to Saudi nursing students using guided reflection on clinical vignettes
}

\author{
Eman R. Ahmad ${ }^{1,2}$, Nourah Hasan Al Qahtani ${ }^{2}$, Hoda Nafee ${ }^{2,3}$, Mohamed Al-Eraky*2,4 \\ ${ }^{1}$ Assiut University, Assiut, Egypt \\ ${ }^{2}$ University of Dammam, Dammam, Saudi Arabia \\ ${ }^{3}$ Mansoura University, Mansoura, Egypt \\ ${ }^{4}$ Zagazig University, Zagazig, Egypt
}

Received: June 29, 2017

DOI: $10.5430 /$ jnep.v8n1p1
Accepted: August 6, 2017

URL: https://doi.org/10.5430/jnep.v8n1p1
Online Published: August 14, 2017

\begin{abstract}
Background and objective: Professionalism has to be explicitly taught in clinical rotations, yet little is reported about approaches for teaching professionalism in undergraduate nursing education. This study aims to educate undergraduate nursing students on professionalism using guided reflection on clinical vignettes.

Methods: Real-life vignettes were designed to describe common professionalism dilemmas in Obstetrics and Gynecological Nursing curriculum. Teachers used a set of seven questions to trigger discussions and guide reflection on each vignette. During the session, observation notes were taken by peers on teachers' performance, students interaction and group dynamics during the sessions. After the session, students fill in a survey to report their feedback on the sessions.

Results: A total of 91 third-year nursing students participated in the study felt as if they are professional nurses who manage real cases, with feedback from teachers. Students - in groups - were able to indicate stakeholders in each dilemma and advocate their decision. They enjoyed the sessions the highest mean $(4.48 \pm 0.93)$ and felt more prepared to encounter similar situations in their future clinical practice.

Conclusions: Interactive sessions of guided reflections on professionalism dilemmas enabled students to reflect as individuals and in groups, to respect the scope of practice and acknowledge perspectives of different stakeholders. Apart from students' feedback, teachers acknowledged essential competencies that have to be addressed while dealing with professionalism dilemmas. A couple of strategies were recommended for teaching professionalism in nursing education using guided reflection. Nursing students need to learn about: emotional intelligence, risk estimation, and strategies for interference in cases of conflict with colleagues, patients and their relatives, doctors in charge, and the fetus, if applicable, in Obstetrics. Guided reflection sessions on clinical dilemmas were found effective to teach professionalism in nursing students in Obstetrics and Gynecological nursing clinical experience.
\end{abstract}

Key Words: Professionalism, Nursing education, Reflection, Vignettes, Obstetrics \& gynecology, Undergraduates, Clinical experience

\section{INTRODUCTION}

Professionalism remains one of the most challenging competencies to define, teach and assess, because of its complex and context-specific nature. For decades, professional values and behaviors have been caught from role-models through an informal process of socialisation. ${ }^{[1]}$ Role-modelling remains important, but not enough for socialization to acquaint nursing students with the norms and expectations of the nurs-

*Correspondence: Mohamed Al-Eraky; Email: maleraky@uod.edu.sa; Address: University of Dammam, Dammam, Egypt. 
ing professionals, because of the emerging complexity of clinical practice and the heterogeneity of students who enter are recruited from diverse social, cultural and socioeconomic backgrounds. ${ }^{[2]}$ Now a better informed community is asking for accountability, transparency and sound professional standards to meet their expectations. ${ }^{[3-5]}$ Carlson and colleagues advocated that professional localization of nurses is promoted by clinical experience and how nurses think and act as preceptors, hence providing a base for professional socialization to occur, ${ }^{[6,7]}$ where professional value development can be measured at difference stages of nursing education in pre-licensure nursing students in associate degree, diploma, and baccalaureate programs. ${ }^{[8]}$ Professionalism, therefore, must be explicitly planned and taught, using interactive lectures, role-playing (simulation), peer-assisted learning and reflective writing. Understanding how nursing students experience professionalism is important to provide appropriate educational experiences to foster this aspect of professional socialization. ${ }^{[9]}$

Scholarly articles suggested general principles ${ }^{[2]}$ and practice tips $^{[10]}$ for teaching professionalism across the continuum of medical and nursing education, yet little was reported about teaching professionalism in undergraduate nursing education. Two schools of thoughts guide the teaching and learning of professionalism. The first one registers a list of professional values and attributes of health practitioners, as reported by the ABIM framework ${ }^{[11]}$ or the Four-Gates model ${ }^{[12]}$ in the Arabian context. The Four-Gates model include eight attributes that acknowledges spirituality aspects in professionalism, which is not only pertinent to faith or Islamic principles, but also relevant to the humanistic core values of respect for privacy, dignity and religious and cultural beliefs. These humanistic values were reported in the UK Patient Chapter, which further advocates the value of spirituality in nursing practice, ${ }^{[13]}$ which has been reflected in the context-specific studies on professionalism in nursing (apart from Western context) in Iran, ${ }^{[14]}$ Japan, ${ }^{[15,16]}$ Korea $^{[17]}$ and Hong Kong. ${ }^{[18]}$

The second school portrays professionalism as a normative belief system about how best to organize and deliver healthcare. ${ }^{[19]}$ The two schools are not contradicting each other, but complimentary as they engage not only the minds, but also the hearts and souls of professionals. ${ }^{[20]}$ That said, formal lectures on the attributes and behaviors of an "ideal" nurse was not found effective, because the rationale (why factor) is usually missing in these discussions. ${ }^{[21]}$ Nursing students and residents should discuss the rationale to follow a particular course of actions by indicating stakeholders in the situation and learn the options available to decide and the consequences of each decision on different stakeholders including students' opinion. The theoretical basis for teaching professionalism incorporate a number of theories, mainly the situated Learning Theory, ${ }^{[22,23]}$ which assumes that learning is fundamentally a social process and not solely in the learner's head. Therefore, teaching professionalism should be based on reflection on vignettes ${ }^{[24,25]}$ that demonstrate common professionalism dilemmas. Professionalism can be taught through vignettes either written, displayed in role-plays (simulations) or recorded video from real practice. ${ }^{[24,25]}$ Popular medical drama can also present a wealth of situations depicting un/professional manners and selected clips can be used as triggers for reflection on specific professionalism dilemmas or discussing particular behaviours. ${ }^{[26,27]}$

Reflection is the process of analysis, questioning, and reframing (real or simulated) experiences to make an assessment of it for the purposes of learning (reflective learning) and/or to improve practice (reflective practice). ${ }^{[28]}$ Reflection is a method of learning and teaching professional maturity through critical analysis of experience. ${ }^{[29]}$ The use of critical reflection in nursing education was reported as an effective tool to help nursing students learn intellectual capacities to conceptualize knowledge to better meet patients' needs ${ }^{[30]}$ and also to develop their professional identity and public image. ${ }^{[31]}$ Reflective sessions empowers nursing practitioners to achieve and sustain effective practice. ${ }^{[32]}$ Teaching nursing students to reflect on their practice is now the main stream of nursing education in different contexts. ${ }^{[33-35]}$ Yet, reflective practice may not be systematically planned throughout the curriculum, but reflection sessions can be scheduled as a series of isolated, episodic classroom activity. ${ }^{[36]}$

Different approaches, theoretical frameworks and templates for reflection were reported in nursing education. Russell and her colleagues used the SAFETY template that has been developed by the National Council of State Boards of Nursing RN practice to provide nursing students with opportunities to apply concepts in real-world scenarios. ${ }^{[37]}$ SAFETY stands for: System-specific assessment, Assignments and accuracy of orders, First/Priority, Evaluate interventions, Teach and test infection control, C.Y.A/cover your assets. The SAFETY template was pioneered by Rayfield \& Manning as an innovative a useful tool for integration of content knowledge, clinical reasoning, and reflection on essential professional practice issues for baccalaureate nursing students. ${ }^{\left[{ }^{[8]}\right.}$ Other used the so called: Miller's Wheel of Professionalism in Nursing provides a framework for discussion of professional concepts in nursing. ${ }^{[39]}$ The Miller's Wheel has a center that represents the essential foundations of nursing education along with eight spokes to indicate attributes related to competence and continuing education, adherence to code of 
ethics, community services, research, and communication. Yet these attributes are generic and does not support guided reflection on specific scenario. We need to have a shortlist of triggers (questions) that can be used to explore feelings of students and the thought processes in their decision-making.

Nursing students need to reflect on real-life scenarios, which they expect to encounter in clinical practice. Some of the scenarios may be shocking, perplexing and most memorable, as the one reported by Rees et al, when they narrated the story of the "mentor who kicked a dying patient's bed". ${ }^{40]}$ Perception of nursing students on professionalism on different situations according to their educational rank and age. ${ }^{[41,42]}$ Final year nursing students particularly perceived domains like role-modelling, vulnerability, symbolic representation and professional development as elements that informed their own professionalism. ${ }^{[43]}$

In all studies of reflection, proper time should be allocated ${ }^{[10]}$ to explore feelings, question actions, underlying beliefs and values and to solicit different viewpoints to make reflection effective. ${ }^{[44]}$ Teachers and supervisors should prepare a set of questions to trigger guided reflection on common dilemmas in a safe simulated environment during their clinical rotation. This study aims at teaching professionalism using guided reflection on simulated vignettes in Obstetrics and Gynecological Nursing course in undergraduate nursing education.

\section{Methodology}

\subsection{Context}

The current study has been performed at the College of Nursing at Imam Abdul Rahman Bin Faisal University, Saudi
Arabia. The Saudi culture seems conservative and it has been influenced by the religion of Islam, the role of history, and its traditions which makes it different from other cultures even within the Arabian context. In Saudi Arabia male and female students learn in complete separate campuses. Our study accomplished in female section in Obstetrics and Gynecological Nursing training, management of clinical cases rooted mainly in legal and religious backgrounds.

\subsection{Participant}

A total of ninety-one third year nursing students were selected to participate in the study during their clinical rotations in the Obstetrics and Gynecology ward. Nursing students were divided in groups of 10-12 students. Each group was supervised by one faculty/staff member throughout the period of 5 rotations accomplished in ten-week clinical rotation, 2 days per each week in Obstetrics and Gynecology Department at King Fahd Hospital University. Participants did not have any prior orientation sessions or lectures on professionalism over the past two years in their formal curriculum.

\subsection{Methods/Tools for data collection}

Four tools were used for data collection in this study.

Tool (1): A guided vignette was developed by the author that reflect real life situation. The authors reviewed the literature related to professionalism in Arabian context and then developed sample of vignettes address common dilemma related to professionalism in OBGYN nursing practice. Vignettes narrated clinical scenarios from real practice, but not intended to assess students' medical background, but their ability for decision-making in conflict situations. Samples for the vignettes used in the study are listed in Table 1.

Table 1. Sample vignettes in obstetrics and gynecological nursing course indicating dilemmas in nursing professionalism

\begin{tabular}{|c|c|}
\hline Vignette \#1 & $\begin{array}{l}\text { Mrs. X (45 y.) came to your family planning clinic and asked you to give her the Depo-provera injection (progestin-only } \\
\text { contraceptive method) according to the prescription of the gynecologist. On pelvic examination, you discovered that Mrs. X } \\
\text { has query cervical tumour, which is a clear contraindication for Depo-provera injection. The gynecologist has already left } \\
\text { the clinic. }\end{array}$ \\
\hline Vignette \#2 & $\begin{array}{l}\text { While you are working in your first week of residency training, a } 27 \text {-year old gravid 2, para } 1 \text { pregnant woman at } 39 \text { weeks } \\
\text { was attached on fetal monitoring. The obstetrician evaluated the fetal condition and decided that both the patient and her } \\
\text { baby are OK. He then ordered to disconnect the patient for now. Then you observed infrequent variable deceleration. It is } \\
\text { now } 3 \text { AM! }\end{array}$ \\
\hline Vignette \#3 & $\begin{array}{l}\text { Mrs. F ( } 25 \text { y.) came to your family planning clinic and asked you to insert an intrauterine device (IUD), because she } \\
\text { experienced bad side effects with birth control pills. On reviewing her history and general condition, you found no } \\
\text { contraindications to IUD. The gynecologist recommended IUD for Mrs. F. After IUD insertion, you started educating her on } \\
\text { the common problems of IUD. Then you came to know that she has a history of ectopic pregnancy, which is not favorable } \\
\text { with IUD. }\end{array}$ \\
\hline Vignette \#4 & $\begin{array}{l}\text { A } 38 \text { year old G4P2+1, pregnant woman at } 34 \text { weeks of gestation, came to ER complaining of pain in the right leg and its } \\
\text { warm to touch. The doctor ordered to let her go home because it is a harmless varicose vein. }\end{array}$ \\
\hline Vignette \#5 & $\begin{array}{l}\text { A } 28 \text { year old primi-gravida woman, at } 14 \text { weeks of gestation, known case of type II diabetes \& heart disease, came to the ER } \\
\text { complaining of shortness of breath, fatigue and dizziness. On auscultation crackles were heard. Pulmonary edema was } \\
\text { confirmed by X-ray the doctor ordered IV medication and left the ER, while you know this is contraindicated in diabetes and } \\
\text { it can affect the fetus adversely. }\end{array}$ \\
\hline
\end{tabular}


Tool (2): Seven questions were used to trigger reflection and guide discussion on professionalism vignettes during the session, as suggested by Al-Eraky et al. (2015) ${ }^{[45]}$ as listed in Table 2.

Table 2. Seven questions used to guide reflection on professionalism vignettes during the session, as suggested by Al-Eraky et al. $(2015)^{[45]}$

1) Describe your feelings, if you were in that situation.

2) What is the professionalism dilemma of the given scenario?

3) What would you do in that situation? and why?

4) What are the expected consequences of your decision?

5) What if you were in the shoes of the colleague or the patient? (swapping roles)

6) What did you learn from discussing this scenario?

7) Do you feel more prepared in case if you encounter a similar situation in reality?

Tool (3): A self-administered questionnaire Using a 5-point Likert scale with Strongly Agree (5) and Strongly Disagree (1) to assess students feedback regarding scenarios ethical dilemma.

Tool (4): Observation notes were documented by one of the authors on teachers' performance and students' interaction and group dynamics during the sessions.

\subsection{Ethical approval}

The institutional ethics committee of the university approved the study protocol and informed written consent was obtained from all the recruited students in the third year who studied the OBGYN nursing subject. The authors explained the purpose of the study to each group participating in the study.

\subsection{Procedure}

Students were grouped in teams, with ten to twelve students each. A group leader was nominated by students to guide discussions within teams, present the view and feedback of the group and advocate particular course of actions to handle the scenario in a rational and non-judgmental argument under the supervision of two faculty/staff members from Obstetrics and Gynecological Nursing Unit. Teachers distributed one scenario for each group and allocated time for discussion (20 minutes) within the group under guidance and monitoring, followed by 20 to 30 minutes for sharing views and seeking feedback from the instructor on the given scenario. To guide reflection, a battery of seven questions was handed-over to teachers and group leaders and students were requested to address them all in all groups.

The team leader listed the options available for decision in each case and advocate what they preferred and then report the lessons learned from discussing this professionalism vignettes. Teachers guided the groups during the discussions to help students analyzing the conflict in the scenario and nominate all stakeholders who might be affected by the decision, such as: patients, families, colleagues, superiors, subordinates, hospital administration, and legal bodies. The authors intentionally did not provide options for decision to students to trigger their thoughts for the possible decision to be taken.

Teachers provide feedback on the feasibility of decision agreed by the group and discuss the anticipated consequences of each decision. Each session lasted for around 40-60 minutes and ended by asking students to respond to a survey to report their perceptions on the learning experience, using 5point Likert scale (Strongly Agree, Agree, Neutral, Disagree and Strongly Disagree). The last ten minutes was devoted to students to express lessons they learned from the sessions and the teacher confirmed that students learned the intended learning outcomes.

\subsection{Data analysis}

Responses on the Likert scale were analyzed to report descriptive statistics of students' feedback on the survey items on the Likert scale, where Strong Agree $=5$ and Strongly Disagree $=1$. For observation notes taken by peers on teacher's performance and group dynamics, the notes were analyzed by coding and grouping to higher headings (categories) to elaborate on the teaching experience and suggest strategies to improve learning in future sessions.

\section{RESULTS}

A total of 91 female third-year nursing students participated in the study. Table 3 depicted the descriptive statistics of students' responses on the survey that has been distributed after the sessions. Table 3 portrays enjoyment of the session with the highest mean $(4.48 \pm 0.93)$ and they found the guided reflection followed a logical and well-organized sequence $(4.04 \pm 0.84)$. Yet their perception of their ability to set priorities for clinical practice was modest $(2.50 \pm 0.76)$. Most students $(89 \%)$ indicated that time was properly allocated for the session.

Observation notes were taken by peers during the session to describe the teachers' performance and students group dynamics. Students were not clear about the plan of the session, as they used to attend one-way lecture and tuned themselves for the teacher-centered approach for most of their education. This explains why student felt confused at the beginning, because the sessions were not designed as formal lectures to impart knowledge on professionalism, they mostly tried to react and reflect on the scenario in scientific speech not from the ethical dilemma aspect. Students have to learn from the 
dilemma in hand, which fostered highly interactive discussions within groups. Students felt as if they are professional nurses who manage real cases. They had to build a good rationale to support a defensible decision in each vignette. In an informal feedback on the last 10 minutes of each session, students listed a number of benefits they learned during sessions such as being able to: (1) reflect as individuals and in groups, (2) recognize aspects of professionalism dilem- mas, (3) respect the scope of practice of being a nurse as a member of health professional team and (4) acknowledging perspectives of different stakeholders. Students also reported that they felt better prepared to manage similar situations, if they would encounter them in real life practice and moreover, they reported their wishes to apply the professional scenarios in all subjects and being excited to learn their lessons in this interesting manner.

Table 3. Descriptive statistics of students' responses on their learning experience

\begin{tabular}{lll}
\hline Item & Mean & SD \\
\hline I enjoyed the learning experience. & 4.48 & 0.93 \\
The guided reflection followed a logical and well-organized sequence. & 4.04 & 0.84 \\
The clinical vignettes were relevant to my context. & 3.79 & 1.07 \\
I was able to recognize the aspects of the professionalism dilemma. & 3.66 & 1.02 \\
I learned to set priorities in my clinical practice. & 2.50 & 0.76 \\
\hline
\end{tabular}

\section{Discussion}

The current study aimed at teaching professionalism using guided reflection on simulated vignettes in Obstetrics and Gynecological Nursing course in undergraduate third year nursing education. The findings reported students' satisfaction and excitement about the learning experience and they have suggested different courses of actions for each vignette. Some options were risky, such as: wait and observe in critical situations, while others indicate their inexperience with their scope of future practice, such as: contradicting the direct order from the physician. Unlike multiple choice questions, usually there is no one single best answer in professionalism dilemmas. The decision depends on many variables and students need to learn to embrace the most feasible and appropriate (usually not the ideal) decision for given circumstances.

Beyond student satisfaction, we have analyzed the observation notes taken during the sessions to conclude a couple of suggestions to improve teaching professionalism in future sessions of nursing education when dealing with professionalism dilemmas, as follows:

\subsection{Emotional intelligence}

Emotional intelligence (EI) encompasses people's awareness of, and ability to respond to, emotions in themselves and other people. ${ }^{[46]}$ It is a type of social intelligence that involves monitoring, discriminating between and using emotions to guide thinking and actions. ${ }^{[47]}$ In guided reflection, the first question explored students' feeling about the situation. They need to manage their emotions and direct them to decide the best for patients' interests. Yet, in real practice, decision may not be straightforward. In many occasions, conflicts emerge among professionals particularly between doctors and nurses, where each would have different plans for management of the same case. Students need to lean their scope of practice and when (and how) they can interfere in emergency situations.

\subsection{Identification of stakeholders}

Guided reflection in a simulated (safe) environment enable students to pause and view the big picture as external observers. In clinical encounters, there are different stakeholders, including: nurses (her/himself), patients, relatives, doctor in charge, colleagues (other nurses) and hospital administration. Adding more complexity, there is another important person(s) who should be acknowledge in Obstetrics and Gynecology, namely the fetus or the future baby. Nursing students need to carefully reflect on the benefits and interest of each of the above stakeholders and learn how to tackle a reasonable decision for almost all stakeholders. The complexity of engagement of stakeholders varies in different vignettes. For instance, only three people are concerned: nurse, doctor and patients in vignettes \#1 and \#3, while the fetus (future baby) is added in vignette $\# 2$ and $\# 5$, in cases of pregnancy.

\subsection{Risk estimation}

Apart from diagnosis and management, nurses need to estimate the risks and anticipate the consequences of different options. For instance, unlike the cold case of the varicose veins (vignette \#4), the deceleration in fetal monitoring (vignette \#2) is a serious sign that mandates immediate interference. As part of their emotional intelligence, nurses should learn when to call the doctor at $3 \mathrm{AM}$ and how to communicate bad news, perhaps in a role-play over the phone. 


\subsection{Strategies for interference}

When nurses have to interfere in serious cases or even to overrule physician order (as in vignettes \#2 and \#3), they need to be oriented about the hospital policies for documentation and reporting. Nurses should be educated about the scope of their practice, job descriptions and their privileges. They should also acknowledge the hierarchical structure and the power distance within the unit, while keeping a senior person (such as a head nurse) updated all the time. A senior nurse can suggest other options based on her experience with hospital policies and personal relationships with other staff members. Sometimes another colleague has to be engaged and the dilemma has to be properly handed-over to the nurse of the next shift to manage.

The above competences have to be planned (as learning outcomes) and carefully addressed in designing sessions for guided reflection on professionalism dilemmas in undergraduate nursing education.

\subsection{Implications for nursing educators}

We advocate that the use of guided reflection on clinical vignettes helps students to explore different views and elements on each professionalism dilemma. Teachers should not preach what should be done, but enable students to negotiate the most feasible and appropriate decision in each situation. It would be great that each institution could develop its own bank of vignettes on professionalism dilemmas, with different tags according to: learning outcomes, complexity/level, stakeholders, options for decisions and expected consequences on each decision. Teachers can share their experience with using these vignettes in clinical rotations and update them according to new hospital policies or emerging situations. Finally, we acknowledge that developing clinical vignettes on professionalism is not just about story-telling. The scenario should depict a dilemma with conflicts among different stakeholders to achieve a particular learning outcome. Also guided reflection has to be well-planned using a battery of questions (as listed in Table 2) to align discussion towards the learning outcome.

\subsection{Limitations and venues for future research}

The current study is not without limitation. We measured students' feedback on the sessions using a survey, due to limited availability of students and their tight schedule in clinical rotations. It would be even better to allocate enough time after the sessions - to explore their views, using qualitative approaches, such as: focus group discussions or nominal group techniques. Apart from guided reflection sessions, there is a need to study how students (and residents) can learn about professionalism by documenting their own views on the most impressive clinical experiences, most difficult situations, and most challenging cases. They can keep track of their feeling, thoughts and actions across different phases to monitor their learning and seek feedback from peers and senior colleagues on regular basis.

\section{Conclusion}

Guided reflection sessions on clinical dilemmas were found effective to teach professionalism in nursing students in $\mathrm{Ob}$ stetrics and Gynecological Nursing Course. Students felt as if they are professional nurses who manage real cases, with feedback from teachers. They learned to indicate stakeholders in each dilemma and build a good rationale to support a defensible decision in each vignette. Interactive sessions enable students to reflect as individuals and in groups, to respect the scope of practice and acknowledge perspectives of different stakeholders. Students also reported that they felt better prepared to manage similar situations, if they would encounter them in real life practice.

\section{BIO STATEMENT}

EMAN R. AHMED, is an Assistant Professor of Obstetrics \& Gynecological Nursing- College of Nursing-Assiut University-Egypt, Nursing Education Department, Maternity \& Child Health Nursing at College of Nursing, Imam Abdulrahman (ex Dammam) University, KSA.

NOURAH H. AL QAHTANI, is a Consultant Obstetrician and Gynecologist and an Associate professor, College of Medicine at Imam Abdulrahman Bin Faisal (ex Dammam) University, Saudi Arabia. She is also a fellow of the Royal College of Obstetricians and Gynecologists and has been involved in teaching undergraduate medical and nursing students and postgraduate medical doctors and nurses for more than 25 years.

HODA M. NAFEE, is a Lecturer of pediatric nursing, College of Nursing, Mansoura University, Egypt. She also is an Assistant Professor at College of Nursing, Maternity \& Child Health Nursing at College of Nursing, Imam Abdulrahman Bin Faisal (ex Dammam) University Saudi Arabia.

MOHAMED MOSTAFA AL-ERAKY, $\mathrm{PhD}$, is an Assistant Professor of Medical Education and Director for Development \& Academic Initiatives at Imam Abdulrahman Bin Faisal (ex Dammam) University, Saudi Arabia. He was also a founding member of Medical Education Development Center at Zagazig University, Egypt. Medical professionalism has been the foremost area of interest and scholarship of Dr. Al-Eraky throughout his master from Dundee (UK) and $\mathrm{PhD}$ studies in health professions education from Maastricht (the Netherlands). 


\section{REFERENCES}

[1] Loh KY. Nalliah S. Learning professionalism by role-modelling. Med. Educ. 2010. PMid:20963918 https://doi.org/10.1111/j.13 $65-2923.2010 .03827 \cdot x$

[2] Cruess RL, Cruess SR. Teaching professionalism: general principles. Med. Teach. 2006. PMid:16753716 https://doi.org/10.1080/ 01421590600643653

[3] Reid L. Medical professionalism and the social contract. Perspect. Biol. Med. 2011. PMid:22019534 https://doi.org/10.1353/ pbm. 2011.0048

[4] Welie JVM. Social contract theory as a foundation of the social responsibilities of health professionals. Med. Health Care. Philos. 2012. PMid:22002433 https ://doi .org/10.1007/s11019-011-935 5-7

[5] Cruess SR, Cruess RL, Steinert Y. Linking the teaching of professionalism to the social contract: a call for cultural humility. Med. Teach. 2010. PMid:20423251 https://doi .org/10.3109/0142 1591003692722

[6] Carlson E, Pilhammar E, Wann-Hansson C. 'This is nursing': Nursing roles as mediated by precepting nurses during clinical practice. Nurse Educ. Today. 2010. PMid:20378215 https ://doi .org/10 $.1016 / j$.nedt .2010 .01 .020

[7] Clark CL. The Professional Socialization of Graduating Students in Generic and Two-Plus-Two Baccalaureate Completion Nursing Programs. J. Nurs. Educ. 2004. PMid:15344370

[8] Fisher M. A Comparison of Professional Value Development Among Pre-Licensure Nursing Students in Associate Degree, Diploma, and Bachelor of Science in Nursing Programs. Nurs. Educ. Perspect. 2014. PMid:24716340 https://doi.org/10.5480/11-729.1

[9] Secrest J, Norwood BR, Keatley VM. 'I was actually a nurse': the meaning of professionalism for baccalaureate nursing students. J. Nurs. Educ. 2003. PMid:12622335

[10] Al-Eraky MM. Twelve Tips for teaching medical professionalism at all levels of medical education. Med. Teach. 2015. PMid:25776227 https://doi.org/10.3109/0142159X.2015.1020288

[11] ABIM (American Board of Internal Medicine). Project Professionalism. 1995. Available from: http://www.abimfoundation.org / /media/Foundation/Professionalism/Projectprofessi onalism.ashx?la=en (Accessed: 23rd December 2014)

[12] Al-Eraky MM, Donkers J, Wajid G, et al. A Delphi study of medical professionalism in Arabian countries: the Four-Gates model. Med. Teach. 2014.

[13] Gilliat-Ray S. Nursing, professionalism, and spirituality. J. Contemp. Relig. 2003. https://doi.org/10.1080/135379003100 01601695

[14] Dehghani A, Salsali M, Cheraghi MA. Professionalism in Iranian Nursing: Concept Analysis. Int. J. Nurs. Knowl. 2016. PMid:25784268 https ://doi .org/10.1111/2047-3095.1208 2

[15] Tanaka M, Yonemitsu Y, Kawamoto R. Nursing professionalism: A national survey of professionalism among Japanese nurses. Int. J. Nurs. Pract. 2014. PMid:24124895 https ://doi .org/10.1111/ ijn. 12201

[16] Tashiro J, Shimpuku Y, Naruse K, et al. Concept analysis of reflection in nursing professional development. Japan Journal of Nursing Science. 2013. PMid:24373440 https://doi.org/10.1111/j.17 42-7924.2012.00222.x

[17] Hwang JI, et al. Professionalism: The major factor influencing job satisfaction among Korean and Chinese nurses. Int. Nurs. Rev. 2009. PMid:19702804 https://doi.org/10.1111/j.1466-7657.20 09.00710.x

Published by Sciedu Press
[18] Wong EML, Lau PF. Evolving towards professionalism in emergency nursing in Hong Kong. Int. Emerg. Nurs. 2008. PMid:18519054 https://doi.org/10.1016/j.ienj.2007.11.008

[19] Wynia MK, Papadakis MA, Sullivan WM, et al. More than a list of values and desired behaviors: a foundational understanding of medical professionalism. Acad. 2014. PMid:24667515 https: //doi.org/10.1097/ACM. 0000000000000212

[20] Wood W. The heart, mind, and soul of professionalism in occupational therapy. Am. J. Occup. Ther. 2004. PMid:15202622 https://doi.org/10.5014/ajot.58.3.249

[21] Nomura H. Developing the 'why' facet of medical professionalism Kaohsiung J. Med. Sci. 2008. https://doi .org/10.1016/S160 7-551X (08) 70070-6

[22] Lave J. Wenger E. Situated Learning: Legitimate Peripheral Participation. Cambridge University Press. 1991. https : //doi .org/10 $.1017 /$ CB09780511815355

[23] Yardley S, Teunissen PW, Dornan T. Experiential learning: AMEE Guide No. 63. Med. Teach. 2012. PMid:22289008 https://doi. org/10.3109/0142159X.2012.650741

[24] Boenink AD, de Jonge P, Smal K, et al. van Tilburg, W. The effects of teaching medical professionalism by means of vignettes: an exploratory study. Med. Teach. 2005. PMid:16147796 https : //doi.org/10.1080/01421590500069983

[25] Bernabeo EC, Holmboe ES, Ross K, et al. The utility of vignettes to stimulate reflection on professionalism: theory and practice. Adv. Health Sci. Educ. Theory Pract. 2013. PMid:22717991 https : //doi.org/10.1007/s10459-012-9384-x

[26] Pavlov A, Dahlquist GE. Teaching Communication and Professionalism Using a Popular Medical Drama. 2010.

[27] Hirt C, Wong K, Erichsen S, et al. Medical dramas on television: a brief guide for educators. Med. Teach. 2013. PMid:23228106 https://doi.org/10.3109/0142159X.2012.737960

[28] Aronson L. Twelve tips for teaching reflection at all levels of medical education. Med. Teach. 2011. PMid:20874014 https ://doi .org/ 10.3109/0142159X.2010.507714

[29] Durgahee T. Promoting reflection in postgraduate nursing: a theoretical model. Nurse Educ. Today. 1996. https://doi.org/10.101 6/S0260-6917 (96)80048-7

[30] Butler KM. The use of critical reflection in baccalaureate nursing education. Nursing Leadership Forum. 2004. PMid:15495761

[31] Hoeve Y, Jansen G, Roodbol P. The nursing profession: Public image, self-concept and professional identity. A discussion paper. J. Adv. Nurs. 2014. PMid:23711235 https://doi.org/10.1111/ jan. 12177

[32] Johns C. Reflection as empowerment? Nurs. Inq. 1999. PMid:10696210 https://doi.org/10.1046/j.1440-1800.19 $99.00038 . \mathrm{x}$

[33] Nicholl H, Higgins A. Reflection in preregistration nursing curricula. J. Adv. Nurs. 2004. PMid:15154898 https://doi.org/10.1111/ j.1365-2648.2004.03048.x

[34] Dekker-Groen AM, van der Schaaf MF, Stokking KM. Teacher Competences required for developing reflection skills of nursing students. J. Adv. Nurs. 2011. PMid:21332576 https://doi .org/10.1111/ j.1365-2648.2010.05591.x

[35] Hannigan B. A discussion of the strengths and weaknesses of 'reflection' in nursing practice and education. J. Clin. Nurs. 2001 PMid:11820349 https://doi.org/10.1046/j.1365-2702.20 01.00459.x

[36] O'Connor A, Hyde A. Teaching reflection to nursing students: a qualitative study in an Irish context. Innov. Educ. Teach. Int. 2005 https://doi.org/10.1080/14703290500291842 
[37] Hicks Russell B, Geist MJ, House Maffett J. SAFETY: an integrated clinical reasoning and reflection framework for undergraduate nursing students. J. Nurs. Educ. 2013. PMid:23244194 https : //doi.org/10.3928/01484834-20121217-01

[38] Rayfield SW, Manning L. Pathways to teaching nursing: Keeping it real. (I Can Publishing, 2006).

[39] RHODES MK, SCHUTT MS, LANGHA GW, et al. The Journey to Nursing Professionalism: A Learner-Centered Approach. Nurs. Educ. Perspect. 2012. PMid:22416537 https : //doi .org/10.5480/15 36-5026-33.1.27

[40] Rees CE, Monrouxe LV, Mcdonald LA. 'My mentor kicked a dying woman's bed...' Analysing UK nursing students' 'most memorable' professionalism dilemmas. J. Adv. Nurs. 2015. PMid:24916272 https://doi.org/10.1111/jan.12457

[41] Akhtar-Danesh N, et al. Perceptions of professionalism among nursing faculty and nursing students. West. J. Nurs. Res. 2013 PMid:21576400 https : //doi .org/10.1177/01939459114086 23

[42] Nath C, Schmidt R, Gunel E. Perceptions of professionalism vary most with educational rank and age. J. Dent. Educ. 2006. PMid:16896085
[43] Keeling J, Templeman J. An exploratory study: Student nurses' perceptions of professionalism. Nurse Educ. Pract. 2013. PMid:22652324 https://doi.org/10.1016/j.nepr.2012.05 .008

[44] Gaiser RR. The teaching of professionalism during residency: why it is failing and a suggestion to improve its success. Anesth. Analg. 2009. PMid:19224808 https://doi.org/10.1213/ane.0b013e $3181935 \mathrm{ac} 1$

[45] Al-Eraky MM, Donkers J, Wajid G, et al. Faculty development for learning and teaching medical professionalism. Med. Teach. 2015. PMid:25803591 https://doi .org/10.3109/0142159X.2 015.1006604

[46] Cherry MG, Fletcher I, O’Sullivan H, et al. Emotional intelligence in medical education: a critical review. Med. Educ. 2014. PMid:24712932 https://doi.org/10.1111/medu.12406

[47] Cherry MG, Fletcher I, O'Sullivan H, et al. What impact do structured educational sessions to increase emotional intelligence have on medical students? BEME Guide No. 17. Med. Teach 2012. PMid:22250672 https : //doi .org/10.3109/0142159X . 2 011.614293 